\title{
Leituras da Mimese
}

Alexandrina Angela da Silva Neta

Resumo

Análise da mimese na obra de Platão e Barthes, a partir de 0 demônio da teoria, de Antoine Compagnon, de cujas idéias se discorda parcialmente. Associação da subversão/repressão, supostamente inserida na concepção de mimese desses autores, a um discurso notadamente retórico.

Palavras-chave: Representação. Argumentação. Subversão. Repressão.

Tem-se como ponto de partida, neste trabalho, uma discordância com relação à leitura que Antoine Compagnon faz, em seu livro $O$ demônio da teoria, da mimese em Platão e Barthes. Compagnon diz que a mimese em Platão é considerada subversiva e, em Barthes, repressiva e também que para receber qualificativos tão distanciados não se trata da mesma noção, que de Platão a Barthes essa noção foi invertida. O autor propõe, ainda, sair da alternativa entre a literatura falar do mundo ou da própria literatura, ou seja, estabelece o caminho da aporia (COMPAGNON, 1999, p. 98-99).

Quanto a Platão, concorda-se com Antoine Compagnon com relação à mimese ser considerada subversiva, mas discorda-se das colocações que justificam essa consideração. Compagnon diz que Platão é tão normativo que expulsa os poetas da cidade. Quando contextualizada, porém, essa expulsão pode tomar um sentido muito diferente de quando vista isoladamente. Então, talvez não se deva simplesmente pensá-la em si, mas sim considerar os motivos que a condicionam. E o que parece é que havia três grandes grupos - poetas, retores, filósofos - sem limites definidos, mas possuindo (todos eles) o lógos como matéria de ofício. Venha daí, talvez, a insistência de Platão em denominar a sua prática de filosofia, estabelecendo esta como superior à poesia e à retórica, ou seja, tornando o seu lógos autorizado. A necessidade de legitimar esse lógos faz-se ainda maior ante a consciência da fragilidade dele. Se a limitação humana é em muito estabelecida pela astenia do próprio lógos, pela sua impossibilidade de dizer o mundo sensível (estabelecer, sem falhas, a relação palavra/coisa), no caso específico de Platão, o lógos é, além disso, impossibilitado de alcançar o mundo inteligível e, portanto, a verdade das coisas. Mas, se, por um lado, o lógos não permite um acesso completo à idéia, por outro, é no seu espaço que se vislumbra a verdade. $\mathrm{O}$ que parece é que é ele o mediador de todo um processo de construção em vários níveis de interesse do filósofo, dos quais cumpre trazer à luz pelo menos dois: habilitar para o exercício autorizado do uso da palavra um certo indivíduo que pretendia fazer desta um modo de vida pautado pela moral e busca da virtude, ou seja, construir o lugar do filósofo e prover a ordenação de uma cidade cuja 
organização assemelhava-se por analogia à alma, também do filósofo. Além disso, o lógos é carecente, é certo, mas ao mesmo tempo forte, capaz, inclusive, de potencializar a construção da cidade; e se Platão a formatou a partir de necessidades reais do mundo sensível, havia a possibilidade de esse mundo ser construído a partir da "cidade do lógos".

Quanto aos poetas, nosso interesse maior, pode-se dizer que Platão era consciente do poder de plasmar que eles tinham e daí a fundação da cidade sobre muitas restrições ao lógos destes. Estas restrições dão-se em termos de lógos propriamente, não se poderia aceitar a fala dos poetas, e principalmente de Homero, que veiculasse ensinamentos indignos; e também em termos de léxis, ou seja, condenava-se a narrativa em discurso direto porque ela possibilitava a irracionalidade da alma. Assim, na cidade "de luxo", era necessário o poeta, mas com restrições estabelecidas pelo filósofo. Se Platão quer delimitar seu próprio lugar, particularizar, quanto aos poetas, a sua teoria propõe a perda da particularidade, daquilo que caracteriza o lógos desse grupo, em especial, a mimese e todo o "inchaço" que faz com que a poesia seja poesia.

É preciso lembrar, também, que há, por detrás de tudo, um autor, que é Platão, mas as falas de cada um, ao longo do texto, não podem ser recortadas, sem que se explicite um contexto, e atribuídas ao pensamento platônico. Por outro lado, Sócrates é um personagem platônico e não uma figura histórica; pode ser que haja muito do Sócrates histórico na República, mas não pode ser menor a medida da construção platônica, uma vez que é mister ter em mente que entre o Sócrates histórico e o Sócrates da República há a mediação do lógos com toda a sua impossibilidade de dizer, assim como o próprio olhar platônico. O mesmo raciocínio de tal construção socrática é válido para os demais participantes do diálogo. A diferença é que, se há entre Platão e Sócrates uma certa identidade (de discípulo e mestre, de amantes da filosofia), ao escrever as falas dos demais, Platão está escrevendo o argumento do outro, o que permite pensar, sob um ponto de vista negativo, a possibilidade de esse discurso já ser tendenciosamente enfraquecido (o narrador é nitidamente socrático) e, sob um aspecto positivo, uma postura interrogativa metodológica despida de preconceitos, possibilitando uma interlocução dialética.

Quanto à mimese, sob a luz da análise retórica, é possível pensá-la em uma nova direção. Não mais simplesmente se Platão, de fato, condena ou não a poesia, mas os elementos condicionantes de tal postura. Se não se pode determinar a realidade de tais elementos, pode-se, ao menos, pela análise, fazer um levantamento deles: tentativa de delimitação de "um lugar", de um lógos autorizado e amor mesmo pela argumentação, pelo diálogo. Aliás, o mesmo amor que permite, ao final da República, a continuação do embate no lógos e nos possibilita questionar a expulsão. E outra vez depara-se com um aspecto negativo e outro positivo, sendo que o primeiro fica por conta da ausência de conclusão (não há um vencedor do embate) como uma descrença nas possibilidades da linguagem; por outro lado, todas as aberturas da discussão (ao longo dos dez livros e mesmo a abertura final para a resposta da poesia) pressupõem a inesgotabilidade do lógos e a perpetuação do embate como uma crença na linguagem, o que não invalida a tentativa de estabelecimento de lugares como elemento causal de tal embate. Mesmo essa delimitação, em termos filosóficos, pressupõe uma disputa sem solução de continuidade: o fim desta significaria, talvez, o fim do lugar do filósofo que, segundo o que parece demonstrar esta obra platônica, é sempre o espaço da busca, da inquirição, da continuidade. O lugar do filósofo está sendo construído é na cidade "inchada" e não na "sã", o filósofo foge para o inteligível, 
desvia-se pela idéia, mas volta para a caverna e convive é com aqueles que prescindem da "acuidade de visão". Assim, mesmo que o discurso platônico seja muitas vezes autoritário, parece estar sempre a deixar a abertura para o outro. Em Platão, o que aparentemente demonstra uma contradição (a consciência da astenia do lógos $\mathrm{X}$ a construção do lugar do filósofo pelo lógos) parece mesmo é confirmar a abertura para as sucessivas possibilidades de resposta, para a perpetuação do embate/diálogo.

Quanto a Barthes, Compagnon considera a mimese repressiva, mas Barthes é teórico de muitas faces. Então, é preciso também contextualizar para que se possa falar com mais segurança. Em Aula, Barthes considera a língua como um lugar repressor, mas apresenta a literatura como a possibilidade de revolução da linguagem e a máthesis, a mímesis e a seméiosis como as três grandes forças da literatura.

Quanto à máthesis, é a arte de ensinar e, para Barthes, a literatura possui sempre muitos saberes, mas não funciona como veículo de comunicação porque ela teatraliza a própria linguagem e mesmo o discurso da ciência supõe ter uma linguagem mais direta do que possui. Na verdade, a arte de ensinar estaria ligada à retórica, uma vez que é por esta que a educação se efetiva. Mas a retórica, para Barthes, possui também um significado especial, pois ele denomina retórica aquilo que se conhece como literariedade/literaturidade ou poética. Então, a máthesis não é mais aquela de um corpus de textos sacralizados.

Já quanto à mímesis, a força de representação, para Barthes, se se pretende ter a realidade como referente, chega-se, no máximo, a uma "ilusão referencial", efetivada, principalmente, por meio dos "pormenores" que produzem um "efeito de real", mas, em verdade, aqueles dizem apenas do processo e não da realidade propriamente dita. Então, a literatura não fala do mundo, mas da própria literatura. Além disso, dentre outras coisas, segundo Barthes, o próprio realismo sempre se definiu mais por seu conteúdo (o prosaico, o trivial etc.) que por sua técnica.

Quanto à seméiosis, o seu próprio objeto já seria impuro, diferentemente da lingüística, segundo Barthes. Também, para ele, a semiologia foi vitoriosa no que se refere à própria renovação devido ao contato com outras "ciências", "disciplinas" e "exigências". Daí o caráter questionador próprio dessa ciência e a crítica da própria semiologia, renovando-se, possibilitando a festa sígnica, não se restringindo ao lugar fechado da legislação.

Então, pode-se entender por que a "força da literatura" que nos interessa mais de perto, a mímesis, recebeu tratamento novo e é considerada subversiva, diferentemente do que Compagnon determina (sem as devidas contextualizações).

É preciso lembrar que o representante, para Compagnon, corresponde à literatura e é fixo: a literatura fala do mundo ou a literatura fala da literatura.

Esquematizando:
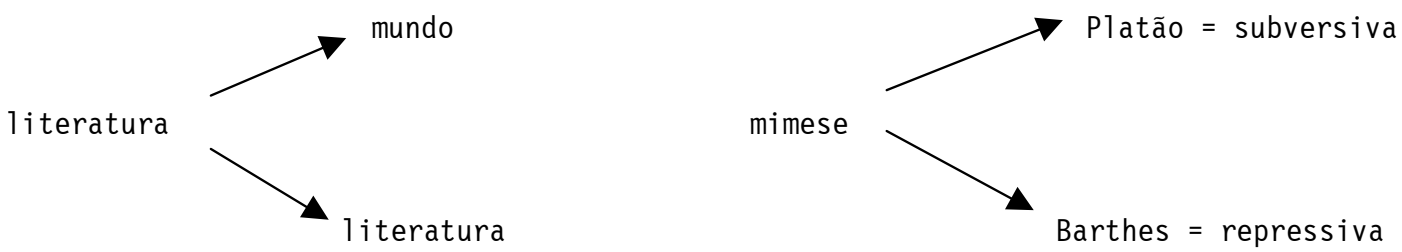

Considerando a mimese repressiva em Barthes, Compagnon está, então, indiretamente, considerando a própria literatura. Mas, conforme demonstrado, Barthes faz uma distinção entre língua = repressão e literatura = subversão. 
O que parece é que a subversividade do discurso em Aula torna-se também um exemplo da noção particular de língua e literatura em Barthes. Compagnon diz, no texto "Lequel est le bon?" (<http://www.fabula.org>), com muito acerto, que não é possível estabelecer rigidamente essa diferença. Entende-se, porém, que Barthes também não estivesse preocupado em estabelecê-la. As suas definições parecem escapar a noções fechadas. O próprio texto Aula não é literatura no sentido de ficção, mas também não é um discurso acadêmico nos moldes tradicionais; e, se não se consegue encaixá-lo em uma designação, é possível, não obstante, sentir sua força provocadora, a capacidade de subversão de sua teia discursiva, o que, talvez, faça dele um texto de língua "ativa" (para usar a própria expressão de Barthes, indicativa do texto subversivo), bem como de uma pístis eficiente. A eficiência da pístis em Aula, no entanto, parece não se dar no sentido de se convencer da validade de uma ideologia ou uma teoria fixas. Uma parte dos leitores de Barthes diz que essa eficiência é coerente com o procedimento do autor, se se considera a sutileza de um sujeito que está em constante deslocamento tão logo o que um dia foi subversivo se estabilize. Há quem critique tal postura, alegando ser isso uma escora de crítico que não quer assumir a sua fala. Foge aos objetivos deste trabalho estabelecer juízo de valor a respeito de Roland Barthes e de sua obra. Mas o certo é que ele rompe com aquilo que se conhece por pacto de leitura e mistura os gêneros, desestabilizando um pouco seu leitor.

Pode-se dizer mesmo que muitas das dificuldades da leitura de Barthes advêm das suas constantes mudanças. Por exemplo: embora, em O grão da voz, ele atribua um caráter reacionário à máthesis e à mímesis, fazendo com que somente a seméiosis assuma um sentido mais libertário, em Aula e em outros textos, fica clara a singularidade do uso desses termos; quanto à máthesis e à mímesis, para Barthes, respectivamente, o texto não funciona como um instrumento e não representa o mundo. Daí, mais uma vez ser inadmissível considerar, com Compagnon, a mimese repressiva em Barthes, sem que pelo menos se especifique de qual mimese se está falando.

De um modo geral, em relação à mimese, pode-se falar em três grandes direções no que concerne à referência, respeitando-se, é claro, diferenças menores entre (e dentro de) determinados períodos, bem como as próprias características individuais. Grosso modo, pode-se dizer, então, que a arte, em geral, pretendeu voltar-se para o mundo exterior ao indivíduo, para o mundo interior deste ou para a própria arte.

Dos autores em questão, Platão assenta-se nesse primeiro caso, se se pensa, por exemplo, que a literatura, para ele, é cópia; ressalvando-se, embora assim, que sua mimese não corresponde exatamente à imitatio, pois o filósofo demonstra consciência da astenia do lógos. Já Barthes agrupa-se no último, se se lembra que está o tempo inteiro a negar a referência exterior à própria arte. Compagnon, por sua vez, embora determine que seguirá um caminho entre a referência ao mundo ou à própria literatura (e de certa forma o segue, quando apresenta posições extremadas), parece estar sempre mais próximo ao mundo que à literatura (e não se está dizendo que isso seja ruim), apresentando muitas contraposições, em seu livro $O$ demônio da teoria, aos teóricos, principalmente a Barthes, que defendem a irreferencialidade.

O problema maior, então, no livro de Compagnon, em geral, e na análise de Platão e Barthes, em especial, parece ser mesmo a ausência de contextualização e de distinções necessárias. Compagnon compara a mimese em Platão e Barthes, mas reconhece que para que ela receba qualificativos tão distanciados (subversiva e repressiva, respectivamente), não se trata da mesma noção. Se essa assertiva, no que 
diz respeito a não se tratar da mesma noção, é válida, não parece ser a noção diferente em cada um que estabelece os qualificativos diferentes, porque, conforme já visto, a mimese com uma noção muito propriamente barthesiana, muito diferente da concepção platônica, é também subversiva. Aliás, cumpre lembrar que existem várias concepções de mimese não só de um modo geral, mas mesmo em cada um dos autores em questão.

Em Platão, pode-se dizer que há, pelo menos, três espécies de mimese: a literatura falando da natureza (considerando esta como o mundo sensível), condenada por ser de terceira ordem; a literatura falando da literatura, condenada principalmente na figura de Homero, por servir de arkhé em dois sentidos: princípio (modelo) e poder (de influenciar outros poetas); a literatura como representação (gênero trágico), condenada por propiciar a irracionalidade. (Parece nunca ser demais lembrar a relatividade dessas condenações.)

Já Barthes, por vezes, quando trata a mimese como repressiva, é à mimese considerada como imitação que se refere (talvez venha daí a leitura de Compagnon), e não à mimese segundo suas próprias definições. A mimese de Barthes, subversiva, é aquela que é uma "força" da literatura e fala da literatura.

Compagnon parece, então, desconsiderar sutilezas próprias de Platão e Barthes. Quanto ao primeiro, o que mais salta aos olhos é uma leitura da expulsão dos poetas descontextualizada e radical; quanto ao segundo, uma leitura literal de suas oscilações, ao que tudo indica, propositais. Parece ter sido tal leitura que fez com que Compagnon considerasse a mimese repressiva em Barthes (sem maiores explicações) em contraposição à mimese subversiva em Platão, sendo que, com relação ao representante, Platão e Barthes parecem tratar daquilo que não se sabe definir exatamente, mas que se reconhece como literatura e, quanto a esta, o que parece é que tanto um quanto outro partilham da mesma opinião: ela é subversiva. O que difere é, talvez, o lugar de que se fala. Platão, apesar de ser também um poeta, fala do lugar de filósofo e, portanto, tendo em vista a própria definição do lugar do filósofo, estabelece a defesa da racionalidade e a subversão não é admitida. Barthes fala do lugar de um teórico (quase escritor) e a subversão é aliada, importante, necessária. 0 esquema que parece adequar-se a essa nova postura é:

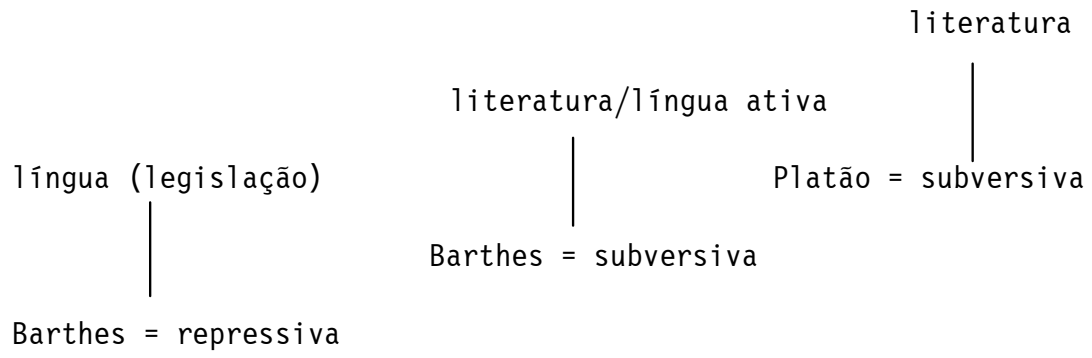

Vale lembrar, ainda, a questão da lei em cada um dos autores. Platão possui uma posição dupla, coloca-se contra a lei vigente (ao elaborar uma nova estrutura para a pólis) e ao lado da lei (quer fazer de suas palavras a nova lei); Barthes se coloca ao lado da literatura (fuga da lei). Ambos reconhecem o poder que a literatura carrega: Platão se empenha (ainda que em tese, "por amor da argumentação") para que esse poder não se alastre sem um determinado controle e direcionamento; Barthes parece desejar apaixonadamente que isso aconteça. 
Assim, no caso de Platão, se se considera não a expulsão em si, mas as razões que a condicionam, pode-se pensá-la determinada por fatores relacionados a delimitação de lugares e a um trabalho mesmo com o lógos, e não a um menor apreço por (ou uma não aceitação dos) poetas; e, então, torna-se possível relacionar a consideração da mimese como repressiva em Platão a uma estratégia substancialmente retórica. Quanto a Barthes, é válido também lembrar que as suas "forças da literatura", máthesis, mímesis e seméiosis, são possuidoras de um grande poder de subversão e se efetivam pela retórica; além disso, Barthes denomina retórica o que se concebe por poética e o seu próprio deslocamento constante parece ser um recurso também retórico.

As análises de Compagnon parecem, então, prescindir de sutilezas: são feitas afirmações condizentes com opiniões já cristalizadas, sem as devidas ressalvas para o contexto. É claro que parte dessa simplificação é justificada pelo próprio caráter do livro $O$ demônio da teoria, que é uma espécie de manual, pois trata de quase todos os temas mais caros à teoria da literatura ao longo de todo o tempo, incluindo, portanto, todos os autores mais significativos. E se, por um lado, o excesso de especialização faz perder a noção da totalidade, o excesso de generalidade desfigura o aprofundamento. Antoine Compagnon parece pecar por esta segunda opção.

Abstract

This paper analyses the mimesis in the works of Platon and Barthes, taking O demônio da teoria, by Antoine Compagnon. Besides this analysis, which partly disagrees with Compagnon's ideas, this paper also associates the subversion/repression supposedly inserted in the two writers' conception of mimesis with a rethorical discourse.

Key words: Representation. Argumentation. Subversion. Repression.

Referências

BARTHES, Roland. Leçon. Paris: Éditions du Seuil, 1978.

BARTHES, Roland. Aula. Tradução Leyla Perrone-Moisés. São Paulo: Cultrix, 1989.

COMPAGNON, Antoine. Le démon de la théorie: littérature et sens commun. Paris: Éditions du Seuil, 1998.

COMPAGNON, Antoine. Le quel est le bon? Disponível em: $<$ http://www.fabula.org >.

COMPAGNON, Antoine. O demônio da teoria: literatura e senso comum. Tradução de Cleonice Paes Barreto Mourão. Belo Horizonte: UFMG, 1999.

PLATÃO. La république / Politeia. Texte établi et traduit par Émile Chambry. In: Oeuvres complètes. Paris: Les Belles Lettres, Tome VI / 1947, Tome VII-première partie / 1949, Tome VII—deuxième partie / 1948. 
Em Tese, Belo Horizonte, v. 10, p. 22-28, dez. 2006

PLATÃO. A República. Tradução de Maria Helena da Rocha

Pereira. 9.ed. Porto: Fundação Calouste Gulbenkian, 2001. 